ISSN:1308-8173

Geliş Tarihi: 09.03 .2019
E-ISSN: $1308-8505$

Kabul Tarihi: 07.11.2019
YIL: 2019

Online Yayın: 08.11.2019
Cilt: 34 Sayı: 3 Sayfa: 413-430

Doi: $10.24988 /$ ije.2019343843

\title{
Fiyat-Duyarlı Talep ve Tarama Kısıtı ile Bir Ekonomik Üretim Miktarı Modeli
}

\author{
Harun ÖZTÜRK ${ }^{1}$
}

Özet

Talep miktarının satış fiyatına karşı duyarlı olması ve kusurlu üretim varsayımlarının optimal politika üzerindeki etkisi birçok üretim probleminde ele alınmıştır. Bu modellerde, tarama işleminin üretim süresi sonunda tamamlandiğı varsayılmıştır. Bu çalışmada, tek kalem ürünün tek bir makinede partiler halinde üretildiği bir üretim sistemi için talep miktarının satış fiyatının doğrusal bir fonksiyonu olduğu varsayımı ile bir ekonomik üretim miktarı modeli gelişstirilmektedir. Üretim sürecinin kusurlu olduğu, tarama işleminin üretimden sonra da devam ettiği ve belirlenen kusurlu ürünlerin tarama süresi sonunda tek parti halinde indirimli fiyattan satıldığı varsayılmaktadır. Bu çalıșmadaki temel amaç, toplam kârı maksimum yapacak üretim miktarı ve satış fiyatının belirlenmesidir. Optimal çözümler önerilen bir algoritma ile elde edilmektedir. Geliştirilen modelin geçerliliğini göstermek amacıyla duyarlllık analizlerine sahip sayısal bir örnek verilmektedir.

Anahtar kelimeler: Stok kontrolü, ekonomik üretim miktarı, kusurlu ürün, fiyatlandırma, fiyat-duyarlı talep, tarama Jel Kodu: C02, C44, L11, M11

\section{An Economic Production Quantity Model with Price-Sensitive Demand and Screening Constraint}

\section{Abstract}

There have been many production problems addressing the effects of price-sensitive demand and imperfect production on optimal policy. These models assumed that screening process is completed at the end of production process. In this paper, an economic production quantity model is developed for a production system where a single item is produced in batches in a single machine by assuming that demand is a linear function of selling price. It is also assumed that the production process is imperfect, the screening process continues after production and the defective products identified are sold as a single batch at a discounted price at the end of the screening period. The main objective of this study is to determine the production quantity and selling price such that the total profit is maximized. The optimal solutions are obtained with a proposed algorithm. A numerical example with sensitivity analysis is given to illustrate the effectiveness of the developed model..

Keywords: Inventory control, economic production quantity, defective item, pricing, price-sensitive demand, screening Jel Codes: C02, C44, L11, M11

\section{GíRiș}

Müşteri taleplerini ihtiyaç hissedilen anda karşılamak ve piyasa gücünü elinde tutmak amacıyla, üretim ya da hizmet sektöründe faaliyet gösteren her işletme belirli bir miktarda stok bulundurmalıdır. Eldeki stok miktarının optimum düzeyde olması, bir yandan üretim seviyesini belirlerken diğer yandan önceden verilen siparişlerin istenilen sayılarda gerçekleștirilmesini sağlamaktadır (Demir ve Gümüşoğlu, 1998: 539-541).

Stok yönetimi, en uygun zamanda ve doğru yerde, minimum maliyetle optimal stok miktarını bulundurmayı amaçlamaktadır.
Talep edilen miktardan daha az stok bulundurmak, tedarik sisteminde aksaklıklara sebep olacağından maliyetleri artırmaktadır, fazla miktarda stok bulundurmak ise uzun vadede rekabeti olumsuz etkilemektedir. Etkili ve verimli bir stok yönetimiyle müșteri istek ve ihtiyaçlarının karşılanması beraberinde müşteri sayısında ve kâr oranında bir artış getirecektir. Bu nedenle, herbir işletme sahip olduğu üretim hacmi ve müşteri potansiyelini göz önüne alarak uygun stok kontrol politikası belirlemelidir (Ulucan, 2004: 374-375).

Günümüzde birçok işletme, stok maliyetlerinin kârlılığa direkt olarak etki ettiğini ve ekonomik olarak fayda sağladığını farkettiğinden, stok

${ }^{1}$ Dr. Öğr. Üyesi, Süleyman Demirel Üniversitesi, İktisadi ve İdari Bilimler Fakültesi, Merkez / ISPARTA, EMAIL: harunozturk@sdu.edu.tr, ORCID: 0000-0003-0193-6663 


\section{H. ÖZTÜRK}

maliyetlerinin azaltılması konusundaki çalışmalarını artırmıştır. Bu bağlamda, birçok araştırmacı ve akademisyen, eldeki stok miktarını ve ortaya çıkan maliyetleri azaltmak amacıyla üretimde ya da satın almada daha doğru kararlar vermeyi sağlayan stok kontrol modelleri geliştirmişlerdir.

Ekonomik sipariş miktarı (ESM) ve Ekonomik üretim miktarı (EÜM) modelleri geleneksel stok kontrol modelleri olarak bilinmektedir. ESM modeli, herbir siparişte tedarikçiden teslim alınacak optimal sipariş miktarını bulmayı hedeflemektedir. Diğer taraftan, EÜM modeli, herbir üretimde üretilmesi gereken optimal üretim miktarını belirlemeyi amaçlamaktadır. Her iki problemdeki temel amaç, sipariş verme ya da üretim hazırlık ve stok maliyetlerinden oluşan toplam maliyeti minimum yapmaktır. $\mathrm{Bu}$ modeller, matematiksel olarak içerdikleri terim sayılarının az olması sebebiyle kullanım kolaylıkları sağlarken, günlük yaşamdan oldukça uzak birçok varsayım içermektedirler. Günümüze kadar bu varsayımların önemli bir kısmı genişletilmiş ve gevşetilmiş, ilgili problemlerin modellenmesine dahil edilerek yeni çözümleri elde edilmiştir. Bu çalışmada ele alınan problem, kusurlu üretim, üretim sırasinda ve üretimden sonra tarama ve fiyatlandırma varsayımlarını içermektedir. Dolayısıyla, çalıșmanın bundan sonraki kısmında literatürde sadece bu varsayımları dikkate alarak model öneren çalışmalara yer verilmiştir.

Geleneksel stok kontrol modellerinden biri olan ESM modeli 1913 yılında Harris tarafından geliştirilmiştir. EÜM modeli ise Taft tarafından 1918 yılında önerilmiştir. EÜM modeli yaklaşık olarak yüzyıl öncesinde stok literatürüne kazandırılmış olsa da, hala bazı gerçekçi olmayan varsayımlara sahiptir. Örneğin, literatür incelendiğinde, birçok çalışmada, fiyatlandırmanın mevcut stok politikası üzerinde herhangi bir etkisinin olmayacağı düşünüldüğünden, bu tür etkilerin matematiksel modellemede dikkate alınmadığ görülmektedir. Bununla birlikte, teslim alınan ya da üretilen herbir partinin sadece kusursuz ürünler içerdiğidir. Yani, üretilen ya da teslim alınan ürünler arasında hiçbir kusurlu ürünün bulunmadığıdır. Halbuki, bu durum, üretim sistemlerinin kusurlu olması, taşıma sırasında ortaya çlkabilecek problemler ve diğer sebeplerden dolayı günlük yaşamda çok da mümkün olmamaktadır.

Porteus (1986), kusurlu ürünler üreten üretim sistemlerinde kusurlu ürünlerin belirli bir maliyetle tekrar işlenebileceği varsayımını dikkate almış, üretim sürecinin kalitesinin iyileştirilmesinin optimal üretim miktarında ve hazırlık maliyetinde bir azalma sağladığını göstermiştir. Aynı yıl içerisinde, Rosenblatt ve Lee (1986), üretim sürecinin, üretime başlandığı andan itibaren iyi kalitede ürünler ürettiğini, ancak, bir zaman sonra üretim sürecinin bozularak düşük kalitede (kusurlu) ürünler üretmeye başladığını ve bu durumun üretim tamamlanıncaya kadar devam ettiğini düşünmüşlerdir. Dahası, üretim sürecinin kontrol dışı olduğu zaman aralığında üretilen düşük kaliteli ürünlerin yeniden işlendiğini ya da tamir edildiğini varsaymışlardır. Daha sonra, Hayek ve Salameh (2001), geleneksel EÜM modelini, üretilen ürünlerin belirli bir oranda yeniden işlenebilir kusurlu ürün içerdiği, kusurlu ürün oranının sürekli tekdüze dağılıma uyan rassal bir değișken olduğu ve bir önceki dönemden karşılanamayan talebin yeni üretimle karşılanması durumu olan stoksuzluk varsayımları ile genişletmişlerdir.

Chiu (2003), üretim sırasında üretilen kusurlu ürünlerin sadece belirli bir oranının yeniden ișlenebilir olduğu, diğer kısmının indirimli fiyattan tek parti halinde satıldı $\breve{g}_{1}$ varsayımlarını dikkate alarak matematiksel bir model önermiştir. Bir sonraki çalışmada Chan vd. (2003), kusurlu ürünler içeren üretim stok modelinde, kusurlu ürünler içerisinde, yeniden işlenebilir, indirimli fiyattan satılabilir ve ıskarta (hurda) olarak ayrılabilir cinsten üç farklı türde değerlendirilebilecek ürünler olduğunu dikkate almışlardır. Flapper ve Teunter (2004), bir üretim probleminde, üretim sırasında üretilen kusurlu ürünlerin 
yeniden işlenebilir oldukları ve üretim tamamlanıncaya kadar stokta bekletildikleri varsayımı ile bu süre içerisinde bozulabilir oldukları varsayımını birlikte ele almışlardır. Jamal vd. (2004), kusurlu ürünler içeren tek dönemli stok kontrol probleminde, kusurlu ürünlerin üretim tamamlandiktan sonra yeniden işlenmesi varsayımını düşünmüşlerdir. Problemdeki temel amaç, toplam maliyeti minimum yapacak üretim miktarını belirlemektir.

Cárdenas-Barrón (2009), Jamal vd. (2004) tarafından ele alınan problemi, stoksuzluk varsayımını ekleyerek genişletmiştir. Ancak, literatürde karşılaşılan kusurlu ürün oranı ile ilgili olarak rassal bir değişken olduğu ve bilinen bir olasılık dağılımına uyduğu varsayımının tersine, bu problemde kusurlu ürün oranının sabit bir değer aldığı varsayılmıştır. Bu varsayım Sarkar vd. (2014) tarafından yapılan çalışmada probleme dahil edilmiş ve kusurlu ürün oranının beta, tekdüze ve gama dağılımına uyan rassal bir değişken olduğu varsayılarak üç farklı model önerilmiştir. Hsu ve Hsu (2014), stoksuzluk durumuna izin veren bir ekonomik üretim miktarı modelinde, kusurlu ürün oranının rassal bir değișken olmasının yanısıra bir sabit olduğu varsayımını ele almışlardır. Kusurlu ürün oranı ile ilgili olarak her iki varsayım için de matematiksel modeli formülleştiriken, kusurlu ürünlerin eldeki stoktan çıkarılması zamanını dikkate alan aşağıdaki üç senaryo geliştirilmiştir: 1) belirlendiği anda stoktan çıkarılır, 2) üretim tamamlandığında ve 3) üretim çevrim süresi sonunda.

Çoğu üretim sistemleri kusurlu ürünler ürettikleri için, bu ürünlerin, işletmelerin faaliyet gösterdikleri endüstri alanlarına ve ürün çeşitlerine göre farklılıklar göstermesi kaçınılmaz olmaktadır. Örneğin, kusurlu ürünler, giyim sektöründe indirimli fiyattan satılabilirken, nihai ürünün çok pahalı olduğu otomotiv endüstrisinde bu ürünlerin yeniden işlenerek ya da tamir edilerek iyi kaliteli ürünler grubuna dahil edilmesi daha ekonomik olmaktadır.
Moussawi-Haidar vd. (2016), kusurlu ürünler için yukarıdaki her iki durumu da dikkate alan bir üretim stok problemi çalışmışlardır. Müșteriye teslim edilecek ürünlerin sadece iyi kaliteli ürünlerden oluşması amacıyla hem üretim sırasında hem de üretimden sonra ürün tarama işleminin yapıldığı ve tarama maliyetlerinin farklı olduğu düşünülmüş ve herbir durum için matematiksel model geliştirilmiştir. Üretim sırasındaki tarama hızının talep hızına eşit olduğu, üretimden sonraki tarama hızının ise talep hızından büyük olduğu varsayılmıştır. Herbir model için üretim miktarını veren eşitlik analitik olarak elde edilmiştir. Sonra, Öztürk (2017), MoussawiHaidar vd. (2016)'nin çalışmalarında kusurlu ürünlerin yeniden işlenmesiyle ilgili olarak geliştirilen modeldeki bazı matematiksel ifadelerin doğru olmadığını göstermiş ve sayısal örnek için yeni optimal çözümler elde etmiştir. Aynı problem Taleizadeh vd. (2019) tarafından ele alınmış ve plastikleştirilmemiş polivinil klorür (UPVC) kullanarak dört farklı tipte kapı ve pencere üreten bir üretim işletmesi için optimum üretim miktarlarını ve toplam karı bulmayı amaçlamışlardır. Cunha vd. (2018) ve Jain vd. (2018) bu konudaki son çalışmalara örnek olarak verilebilir.

Piyasadaki talep satış fiyatına karşı duyarlı olduğundan, fiyatlandırma endüstride ya da bir iş kolunda faaliyet gösteren her işletme için oldukça önem arz etmekte ve hayati bir rol üstlenmektedir. Bu durumun bir sonucu olarak, işletmeler fiyatlandırma politikalarını, hem müşteri potansiyelini artırmak hem de daha fazla gelir elde etmek amacıyla karar vermede alternatif bir seçenek olarak kullanmaktadırlar. Bir stok kontrol probleminin matematiksel formülasyonunda üretim ve/veya sipariş miktarı ile birlikte bir ürüne karşı olan talebi etkileyen faktörlerden biri olan satış fiyatının da bir karar değişkeni olarak belirlenmesi elbetteki ilginç ve gerçekçi bir varsayım olacaktır. Çünkü, fiyatlandırma, ekonomik olarak fayda sağlamakla doğrudan ilişskilidir. Bu nedenle ilgili problem birçok araştırmacı tarafından ele alınmış ve matematiksel modelleri geliştirilmiştir. 


\section{H. ÖZTÜRK}

Goyal (1987), sipariş miktarı ve satış fiyatının karar değişkeni olarak belirlendiği bir stok problemi için matematiksel bir model geliștirmiştir. Lau vd. (2001), sipariş sonucu teslim alınan herbir partide kusurlu ürünler bulunması varsayımı altında bir planlama ufku boyunca alıcı için optimal sipariş miktarı ve satış fiyatını belirlemeyi amaçlamışlardır. Abad (2003) ve Dye (2007), kısmi stoksuzluk varsayımları ile bozulabilir ürünler için ortak fiyatlandırma ve parti büyüklügü politikalarını belirlemişlerdir. Parlar ve Weng (2006), fiyat odaklı bir ortamda fiyatlandırma ve üretim kararlarını birlikte ele almanın, bir işletmenin pozisyonunu iyileştirmedeki etkilerini araştırmışlardır. Sayısal analizler sonucunda, fiyatlandırma ve üretim kararlarını birlikte düşünerek rekabet eden işletmelerin kârlılıklarını artırabileceğini elde etmişlerdir.

Chen ve Bell (2009), talebin bilinmediği durumlarda müşteri iadelerinin, alıcı için ortak fiyatlandırma ve parti boyutu belirleme süreci üzerindeki etkilerini araştırmışlardır. Problem, tek ve çok dönemli stok kontrol modeli olarak formüle edilmiş ve çözümler analitik olarak bulunmuştur. Sajadieh ve Akbari Jokar (2009), iki aşamalı tedarik zinciri problemi için fiyat, sipariș verme sıklığını (sipariș sayısı) ve sipariş miktarını (parti boyutu) belirlemek amacıyla bir bütünleşik (birleștirilmiş) stok kontrol modeli geliştirmişlerdir. Huang vd. (2011), birden fazla tedarikçi, tek üretici ve birden fazla satıcıdan oluşan çok aşamalı bir tedarik zinciri sisteminde optimal fiyat politikasını analiz etmişlerdir. Shi vd. (2012), tedarikçi alıcı ilişkisine dikkati çekerek, tedarikçinin alıcıya sağladığı miktar indiriminin, alıcının teslim aldığı parti boyutu ve uyguladığı fiyatlandırma politikası üzerindeki etkisini incelemişlerdir. Tedarikçi-alıcı problemini, karma tamsayılı doğrusal olmayan programlama ve ayrık programlama modeli ile formüle etmişler ve geliştirilen bir algoritma ile optimal sipariş miktarı, optimal satış fiyatı ve maksimum toplam kârı elde etmişlerdir.

Son bir çalışmada, Taleizadeh vd. (2016), yeniden işlenebilir kusurlu ürünler için bir
EÜM modeli geliștirmișlerdir. Kusurlu ürünler için yeniden işleme operasyonunun üretim tamamlandıktan hemen sonra başladığını ve yeniden işlenen ürünlerden bir kısmının kullanılamaz olduğunu ve hurda olarak ayrıldığını varsaymışlardır. Ayrıca, talep miktarının satış fiyatının doğrusal bir fonksiyonu olması problemdeki diğer bir varsayımdır. Geliştirilen modeldeki temel amaç, toplam kârı maksimum yapacak optimal üretim miktarı ve optimal satış fiyatının elde edilmesidir. Optimal sonuçlar geliştirilen bir algoritma yardımıyla belirlenmiştir. Gürkan vd. (2017), fiyat duyarlı talep varsayımını dikkate alarak stok ve fiyatlandırma politikalarını birlikte düşünen stok kontrol modelleri üzerine bir alan yazın araștırması yapmışlardır. Bu çalışma sonucunda, literatürde yer alan çalışmaların büyük bir kısmının tek kalem ürün için optimal stok ve fiyat politikası belirlediğini gözlemlemişlerdir. Shah vd. (2018) ve San-José vd. (2018), bu konudaki en son çalışmalara örnek olarak verilebilir.

Literatürde, fiyatlandırma ve stok politikalarını birlikte ele alan birçok çalışma bulunmaktadır. Ancak, bu çalışmaların hiçbirinde fiyatlandırma, üretim ve tarama zamanı birlikte ele alınarak optimal politika belirlenmemiştir. $\mathrm{Bu}$ nedenle, bu çalışmada, ürün tarama işleminin hem üretim sırasında hem de üretimden sonra yapıldığı ve kusurlu ürünlerin tarama süreci tamamlandıktan sonra tek parti halinde indirimli fiyattan satıldığı bir stok problemi ilk olarak ele alınmış, matematiksel modeli geliştirilmiş, optimal satış fiyatı ve optimal üretim miktarını veren eşitlikler elde edilmiştir. Bu tür bir varsayım, fiyatlandırma ve kusurlu ürünler içeren stok kontrol problemlerinde birlikte ele alınmamıștır. Bu çalışma, bu yönüyle literatüre katkı sağlamaktadır ve Moussawi-Haidar vd. (2016) tarafından ele alınan problemin genişletilmiş bir halini sunmaktadır.

Çalışma aşağıdaki gibi düzenlenmektedir. İkinci bölümde, çalışmaya konu olan üretim stok kontrol problemi tanımlanmaktadır. Üçüncü bölümde, önce matematiksel modeli 
oluşturmada kullanılacak simgeler verilmektedir, sonra fiyat-duyarlı talep ve tarama kısıtı varsayımları altında yeni bir EÜM modeli geliştirilmektedir. Yine bu bölümde, optimal çözümü elde etmek için bir algoritma önerilmektedir. Dördüncü bölümde, sayısal bir örnek verilmektedir ve duyarlılık analizi ile geliştirilen matematiksel modelin uygulanabilirliği ve geçerliliği gösterilmektedir. Beşinci bölümde, çalışmada elde edilen sonuçlara, kısıtlamalara ve sonraki araştırmalara yer verilmektedir.

\section{PROBLEMIN TANIMI}

Bu çalışmada, Moussawi-Haidar vd. (2016) tarafından geliştirilen model, talep miktarının satış fiyatının doğrusal bir fonksiyonu olması varsamıyla genişletilmektedir. Çalışmaya konu olan stok probleminin bir tanımı aşağıdaki gibidir. Tek kalem ürün tek bir makinede partiler halinde birim zamanda $\alpha$ hızı ile üretilmektedir. $\mathrm{Bu}$ ürüne olan talep birim zamanda $\beta(\beta<\alpha)$ birimdir. Üretim süreci kusurlu ürünler üretmektedir ve üretilen herbir partide $P$ oranında kusurlu ürün bulunmaktadır. Üretilen kusursuz ürünlerin birim satış fiyatı $S^{\prime}$ dir. Kusurlu ürün oranı $P$, bilinen bir olasilık dağılımına uyan rassal bir değişkendir. Herbir üretim çevrim süresi, üç dönemden oluşmaktadır. Birinci dönemde $\left(t_{1}\right)$, hem üretim yapılmaktadır hem de talep karşılanmaktadır. Üretim sırasında talebin sadece kusursuz ürünlerden karşılandığı varsayıldığından, müşteriye gönderilecek herbir parti ancak tarandıktan sonra teslim edilmektedir. Birim tarama maliyeti $\left(d_{1}\right)$ ile gösterilmiștir. Dolayısıyla, eğer bir ürünün kusurlu olduğu belirlenirse, kusursuz bir ürün ile değişimi sağlanmaktadır. Üretim sırasında elde edilen kusurlu ürünler üretim tamamlanıncaya kadar stokta bekletilmektedir. İkinci dönemde $\left(t_{2}\right)$, üretilen partiden elde kalan ürünler için birim zamanda $X(X>\beta)$ tarama hızı ile bir tarama işlemi yapılmaktadır. $\mathrm{Bu}$ dönemde, birim tarama maliyeti $d_{2}\left(d_{2}<\right.$ $d_{1}$ ) ile ifade edilmiştir. Üretim sırasında elde edilen kusurlu ürünler ile tarama sonunda belirlenen kusurlu ürünlerin tamamı $(P Y)$, tarama işlemi tamamlandıktan sonra tek parti halinde indirimli birim fiyatı $V(V<S)$ ile satılmaktadır. Bu çalışmada, $A$ ile indirim oranı ifade edilmiş ve indirimli satış fiyatı $V=(1-$ A)S olarak yeniden tanımlanmıștır. Üçüncü dönemde $\left(t_{3}\right)$, kusurlu ürünlerin tamamının eldeki stoktan çıarılmasıyla geriye kalan kusursuz ürünlerin tüketimi gerçekleşmektedir. Bir önceki dönemden karşılanamayıp ertelenen talebin bir sonraki üretim başladığında karşılandığı stoksuz kalma durumuna izin verilmemektedir. Stok seviyesinin zamanla değişim grafiği Şekil 1 ile verilmektedir.

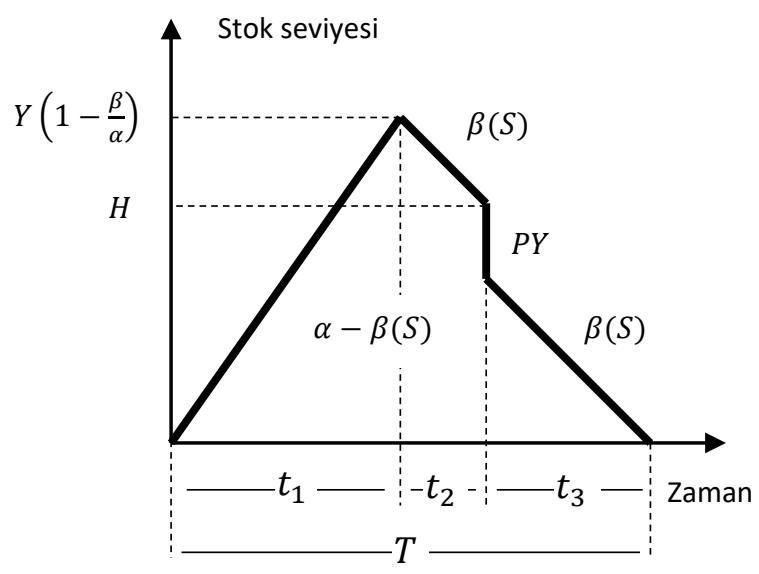

Şekil 1: Stok seviyesinin zamanla değişimi

\section{MATEMATIKSEL MODEL}

$\mathrm{Bu}$ çalışmada ele alınan problem için matematiksel modeli geliştirirken, MoussawiHaidar vd. (2016)'nin matematiksel modellemede ve formülasyonda kullandıkları aynı simgelere yer verilmiştir.

$\alpha \quad$ Üretim hızı

$\beta \quad$ Talep miktarı

$Y \quad$ Üretim miktarı (karar değişkeni)

H Tarama süresi tamamlandığında eldeki stok seviyesi

$T$ Üretim çevrim süresi

$t_{1} \quad$ Üretim süresi 


\section{H. ÖZTÜRK}

$t_{2}$ Üretimden sonraki tarama süresi

$t_{3} \quad$ Tarama süresi tamamlandıktan sonra eldeki kusursuz ürünleri tüketmek için gerekli süre

$K \quad$ Üretim hazırlık maliyeti

$P \quad$ Kusurlu ürün oranı

X Tarama hızı

$d_{1} \quad$ Üretim sırasındaki tarama maliyeti

$d_{2} \quad$ üretimden sonraki tarama maliyeti

$h \quad$ Bir birim ürünü bir birim zaman stokta tutma maliyeti

$S \quad$ Kusursuz ürünler için birim satış fiyatı (karar değişkeni)

$A \quad$ İndirim oranı

$V \quad$ Kusurlu ürünler için birim satış fiyatı

$a, b$ Satıș fiyatına duyarlı talep fonksiyonunun sabit parametreleri, $a>0$ ve $b>0$

\section{$C_{p} \quad$ Birim üretim maliyeti}

$\mathrm{Bu}$ çalışmada, Moussawi-Haidar vd. (2016) tarafından geliştirilen model, talep miktarının satış fiyatının doğrusal bir fonksiyonu olması varsayımıyla tekrar ele alındığından ve matematiksel modeli geliştirileceğinden, (5) eşitliğine kadar olan ifadeler, Moussawi-Haidar vd. (2016)'nin çalışmalarından alınmıştır.

Bir çevrimdeki üretim süresi $\left(t_{1}\right)$, üretim miktarının $(Y)$ üretim hızına $(\alpha)$ oranlanmasıyla elde edilir ve aşağıdaki gibi verilir.

$$
t_{1}=\frac{Y}{\alpha} .
$$

Üretim sırasında kusursuz ürünlerin yanısıra kusurlu ürünlerin üretildiği ve bu zaman aralığında oluşan talebin sadece kusursuz ürünlerden karşılandığg varsayıldığından, talep edilen miktardan daha fazla ürünün taranması gerekmektedir. 0 halde, $\left[0, t_{1}\right]$ zaman aralığında taranan toplam ürün sayısı aşağıdaki eşitlik ile verilir.

$$
\left(\beta+\beta P+\beta P^{2}+\cdots\right) t_{1}=\frac{\beta t_{1}}{1-P}=\frac{\beta Y}{\alpha}\left(\frac{1}{1-P}\right) .
$$

Üretim tamamlandığında belirlenen kusurlu ürün sayısı, $\left[0, t_{1}\right]$ zaman aralığında taranan toplam ürün sayısından yine bu zaman aralığında oluşan talep miktarının çıkarılmasıyla aşağıdaki gibi elde edilir.

$$
\frac{\beta t_{1}}{1-P}-\beta t_{1}=\frac{\beta Y}{\alpha}\left(\frac{P}{1-P}\right) \text {. }
$$

Üretim tamamlandığında eldeki taranmayan ürün sayısı, üretimden sonra ulaşılan maksimum stok seviyesinden $Y(1-\beta / \alpha)$, $\left[0, t_{1}\right]$ zaman aralığında belirlenen kusurlu ürün sayısının $(\beta Y / \alpha)(P /(1-P))$ çıkarılmasıyla elde edilir ve aşağıdaki gibi verilir.

$$
Y\left(1-\frac{\beta}{\alpha}\right)-\left(\frac{\beta Y}{\alpha}\left(\frac{P}{1-P}\right)\right)=Y\left(1-\frac{\beta}{\alpha}\left(\frac{1}{1-P}\right)\right) .
$$

Yine Şekil 1'den aşağıdaki eșitlikler yazılabilir:

$$
\begin{aligned}
& t_{2}=\frac{Y\left(1-\frac{\beta}{\alpha}\left(\frac{1}{1-P}\right)\right)}{X}, \\
& H=Y\left(1-\frac{\beta}{\alpha}\right)-\beta t_{2}, \\
& t_{3}=\frac{H-P Y}{\beta} \\
& T=t_{1}+t_{2}+t_{3} .
\end{aligned}
$$

Bir çevrimdeki toplam gelir $(T R(S, Y))$, kusursuz ürünlerin normal fiyattan ve kusurlu ürünlerin indirimli fiyattan satılmasıyla elde edilir. 0 halde, bir çevrimdeki toplam gelir aşağıdaki gibi ifade edilir.

$$
T R(S, Y)=S(1-P) Y+V P Y
$$

Bu çalışmada farklı olarak, kusurlu ürünlerin indirimli fiyattan $(V)$ satılması varsayımını, indirim oranı $A$ olmak üzere yeni indirimli satış fiyatı $V=(1-A) S$ olarak genişlettik. $\mathrm{Bu}$ 
durumda, bir çevrimdeki toplam gelir $(T R(S, Y))$ aşağıdaki gibi ifade edilir.

$$
\begin{aligned}
& T R(S, Y)=S(1-P) Y+(1-\mathrm{A}) S P Y \\
& =(1-A P) S Y .
\end{aligned}
$$

Bir çevrimdeki toplam maliyet $(T C(S, Y))$, üretim hazırlık, üretim, üretim sırasında tarama, üretimden sonra tarama ve stokta tutma maliyetlerinden oluşmaktadır ve aşağıdaki gibi elde edilir.

$$
\begin{aligned}
& T C(S, Y)=K+C_{P} Y+\frac{d_{1} \beta Y}{\alpha}\left(\frac{1}{1-P}\right) \\
& +d_{2} Y\left(1-\frac{\beta}{\alpha}-\frac{\beta}{\alpha}\left(\frac{P}{1-P}\right)\right) \\
& +\frac{h Y^{2}}{2}\left[\frac{1}{\beta}\left(\left(1-\frac{\beta}{\alpha}\right)^{2}-2 P\left(1-\frac{\beta}{\alpha}\right)+P^{2}\right)\right. \\
& \left.+\frac{1}{\alpha}\left(1-\frac{\beta}{\alpha}\right)+\frac{2 P}{X}\left(1-\frac{\beta}{\alpha}-\frac{\beta}{\alpha}\left(\frac{P}{1-P}\right)\right)\right] .
\end{aligned}
$$

Yukarıdaki eşitlik düzenlenirse,

$$
\begin{aligned}
& T C(S, Y)=K+C_{P} Y+\frac{d_{1} \beta Y}{\alpha}\left(\frac{1}{1-P}\right) \\
& +d_{2} Y\left(1-\frac{\beta}{\alpha}\left(\frac{1}{1-P}\right)\right)+\frac{h Y^{2}}{2}\left[\left(\frac{1}{\beta}-\frac{1}{\alpha}\right)(1-2 P)\right. \\
& \left.+\frac{2 P}{X}\left(1-\frac{\beta}{\alpha}\left(\frac{1}{1-P}\right)\right)+\frac{P^{2}}{\beta}\right] .
\end{aligned}
$$

elde edilir. Bir çevrimdeki toplam kâr $(T P(S, Y))$, toplam gelirden toplam maliyetin çıkarılmasıyla elde edilir, ve aşağıdaki gibi verilir,

$$
\begin{aligned}
& T P(S, Y)=(1-A P) S Y \\
& -\left\{K+\frac{d_{1} \beta Y}{\alpha}\left(\frac{1}{1-P}\right)+d_{2} Y\left(1-\frac{\beta}{\alpha}\left(\frac{1}{1-P}\right)\right)\right. \\
& +C_{P} Y+\frac{h Y^{2}}{2}\left[\left(\frac{1}{\beta}-\frac{1}{\alpha}\right)(1-2 P)\right. \\
& \left.\left.+\frac{2 P}{X}\left(1-\frac{\beta}{\alpha}\left(\frac{1}{1-P}\right)\right)+\frac{P^{2}}{\beta}\right]\right\} .
\end{aligned}
$$

Şekil 1'den üretim çevrim süresinin uzunluğu $(T)$, eldeki kusursuz ürünlerin talep miktarına oranlanmasıyla elde edilir ve aşağıdaki gibi ifade edilir,

$$
T=\frac{(1-P) Y}{\beta} \text {. }
$$

Birim zamandaki toplam kâr $(T P U(S, Y))$, bir çevrimdeki toplam kâr'ın çevrim süresine oranlanmasıyla elde edilir ve aşağıdaki gibi verilir,

$$
\begin{aligned}
& T P U(S, Y)=\frac{T P(S, Y)}{T} \\
& =(1-A P) S Y-\left\{K+C_{P} Y+\frac{d_{1} \beta Y}{\alpha}\left(\frac{1}{1-P}\right)\right. \\
& +d_{2} Y\left(1-\frac{\beta}{\alpha}\left(\frac{1}{1-P}\right)\right)+\frac{h Y^{2}}{2}\left[\left(\frac{1}{\beta}-\frac{1}{\alpha}\right)(1-2 P)\right. \\
& \left.\left.+\frac{2 P}{X}\left(1-\frac{\beta}{\alpha}\left(\frac{1}{1-P}\right)\right)+\frac{P^{2}}{\beta}\right]\right\} .
\end{aligned}
$$

Bu çalışmada, kusurlu ürün oranının $(P)$ rassal bir değișken olduğu ve bilinen bir olasılık dağılımına uyduğu varsayıldığından, üretim çevrim süresinin $(T)$ beklenen değeri aşağıdaki gibi elde edilir,

$$
E(T)=\frac{(1-E(P)) Y}{\beta} .
$$

Ayrıca bir çevrimdeki beklenen toplam gelir ve beklenen toplam maliyet fonksiyonları için sırasıyla aşağıdaki ifadeleri elde ederiz,

$$
\begin{aligned}
& E(T R(S, Y))=(1-A E(P)) S Y, \\
& E(T C(S, Y))=K+C_{P} Y+\frac{d_{1} \beta Y}{\alpha} E\left(\frac{1}{1-P}\right) \\
& +d_{2} Y\left(1-\frac{\beta}{\alpha} E\left(\frac{1}{1-P}\right)\right) \\
& +\frac{h Y^{2}}{2}\left[\left(\frac{1}{\beta}-\frac{1}{\alpha}\right)(1-2 E(P))\right. \\
& \left.+\frac{2 E(P)}{X}\left(1-\frac{\beta}{\alpha} E\left(\frac{1}{1-P}\right)\right)+\frac{E\left(P^{2}\right)}{\beta}\right] .
\end{aligned}
$$

Benzer şekilde, kusurlu ürün oranının $(P)$ rassal bir değişken olduğunu düșünürsek, bir 


\section{H. ÖZTÜRK}

çevrimdeki beklenen toplam kâr aşağıdaki gibi ifade edilir,

$$
\begin{aligned}
& E(T P(S, Y))=(1-A E(P)) S Y \\
& -\left\{K+C_{P} Y+\frac{d_{1} \beta Y}{\alpha} E\left(\frac{1}{1-P}\right)\right. \\
& +d_{2} Y\left(1-\frac{\beta}{\alpha} E\left(\frac{1}{1-P}\right)\right) \\
& +\frac{h Y^{2}}{2}\left[\left(\frac{1}{\beta}-\frac{1}{\alpha}\right)(1-2 E(P))\right. \\
& \left.\left.+\frac{2 E(P)}{X}\left(1-\frac{\beta}{\alpha} E\left(\frac{1}{1-P}\right)\right)+\frac{E\left(P^{2}\right)}{\beta}\right]\right\} .
\end{aligned}
$$

Her üretim çevriminde rassal olarak $P Y$ miktar kusurlu ürün üretilmektedir. Dolayısıyla, üretim çevrim süresinin her çevrim için sabit olması mümkün gözükmemektedir. Yani, üretim çevrim süresi rassal bir değişkendir. Üretim, partiler halinde yapılmaktadır ve herhangi iki üretim sürecinin başlaması arasındaki süre olan çevrim süresi herhangi bir dağılıma uyabilmektedir. Bu durumda, herbir üretimin yenileme sürecine (yenilenen ödül süreci) uygun olarak yapıldığından bahsedebiliriz (Koçer ve Yalçın, 2013). Buradan yola çlkarak, birim zamandaki beklenen toplam kâr $(E(T P U(S, Y)))$, yenilenen ödül teoremi'nden (renewal reward theorem) (Ross, 1996:133), bir çevrimdeki beklenen toplam kârın üretim çevrim süresinin beklenen değerine $(E(T))$ oranlanmasıyla aşağıdaki gibi elde edilir,

$$
E(T P U(S, Y))=\frac{E(T P(S, Y))}{E(T)} .
$$

Eşitlik (20) ile verilen stok problemine, talebi etkileyen faktörlerden biri olan fiyatı (satış fiyatı) dahil etmek amacıyla, talep miktarının satış fiyatının doğrusal bir fonksiyonu olduğu varsayılmaktadır. Bu durumda, talep miktarı aşağıdaki gibi ifade edilmektedir.

$$
\beta=a-b S .
$$

Eşitlik (20)'de talep miktarını $(\beta), a-b S$ ve üretim çevrim süresinin $(T)$ beklenen değerini
$(E(T)), \quad(1-E(P)) Y /((a-b S)) \quad$ ile değiştirirsek, bu durumda birim zamandaki beklenen toplam kâr aşağıdaki gibi elde edilir:

$$
\begin{aligned}
& E(T P U(S, Y))=\frac{(1-A E(P))(a-b S) S}{(1-E(P))} \\
& -\left\{\frac{K(a-b S)}{(1-E(P)) Y}+\frac{C_{P}(a-b S)}{(1-E(P))}+\frac{d_{1}(a-b S)^{2}}{\alpha} \frac{E\left(\frac{1}{1-P}\right)}{(1-E(P))}\right. \\
& +\frac{d_{2}(a-b S)}{(1-E(P))}\left(1-\frac{(a-b S)}{\alpha} E\left(\frac{1}{1-P}\right)\right) \\
& +\frac{h Y}{2(1-E(P))}\left[\left(1-\frac{a-b S}{\alpha}\right)(1-2 E(P))\right. \\
& +\frac{2 E(P)(a-b S)}{X}\left(1-\frac{(a-b S)}{\alpha} E\left(\frac{1}{1-P}\right)\right)+ \\
& \left.\left.E\left(P^{2}\right)\right]\right\} .
\end{aligned}
$$

Yukarıda verilen stok probleminin tekrar düzenlenmesiyle aşağıdaki eşitlik elde edilir,

$$
\begin{aligned}
& E(T P U(S, Y))=(a-b S) S\left[\frac{1-A E(P)}{1-E(P)}\right] \\
& -\frac{K(a-b S)}{Y}\left[\frac{1}{1-E(P)}\right]-C_{P}(a-b S)\left[\frac{1}{1-E(P)}\right] \\
& -\frac{\left(d_{1}-d_{2}\right)(a-b S)^{2}}{\alpha}\left[\frac{E\left(\frac{1}{1-P}\right)}{(1-E(P))}\right] \\
& -d_{2}(a-b S)\left[\frac{1}{1-E(P)}\right]-\frac{h Y}{2}\left[\frac{1-2 E(P)}{1-E(P)}+\frac{E\left(P^{2}\right)}{1-E(P)}\right] \\
& +\frac{h Y(a-b S)}{2}\left[\frac{1}{\alpha}\left(\frac{1-2 E(P)}{1-E(P)}\right)-\frac{2}{X}\left(\frac{E(P)}{1-E(P)}\right)\right] \\
& +\frac{h Y(a-b S)^{2}}{\alpha X}\left[\frac{E(P) E\left(\frac{1}{1-P}\right)}{1-E(P)}\right] .
\end{aligned}
$$

Modelin geçerliliği ile ilgili olarak iki koşulun sağlanması gerekmektedir.

1. Üretim sırasında stoksuzluk durumuna düşmemek için, üretilen kusursuz ürün miktarı, en az üretim zamanında ihtiyaç duyulacak talep miktarı kadar olmalıdır. Yani,

$$
(1-E(P)) Y \geq \beta t_{1} \text { ya da }
$$


İzmir İktisat Dergisi (İzmir Journal of Economics) , Yıl:2019, Cilt:34, Sayı:3, ss. 413-430

$$
E(P) \leq 1-\frac{\beta}{\alpha}
$$

2. Tarama süresinden sonra belirlenen tüm kusurlu ürünler stoktan çıkarıldıktan sonra, eldeki kusursuz ürünleri tüketmek için gerekli süre, sıfırdan büyük olmalıdır. Yani,

$$
\begin{aligned}
& t_{3}>0 \text { ya da } \\
& X>\frac{\beta\left(1-\frac{\beta}{\alpha} E\left(\frac{1}{1-P}\right)\right)}{1-E(P)-\frac{\beta}{\alpha}}
\end{aligned}
$$

\subsection{Optimal çözüm}

$\mathrm{Bu}$ problemdeki temel amaç, birim zamandaki toplam kâr fonksiyonunu maksimum yapacak optimal satıș fiyatı ve optimal üretim miktarını elde etmektir. $O$ halde, birim zamandaki beklenen toplam kâr $\operatorname{E(TPU}(S, Y))$ fonksiyonunun konkav (içbükey) olduğunu göstermek amacıyla aşağıdaki Hessian matrisi (HE) düşünelim.

$$
H E=\left[\begin{array}{ll}
\frac{\partial^{2} E(T P U(S, Y))}{\partial Y^{2}} & \frac{\partial^{2} E(T P U(S, Y))}{\partial Y \partial S} \\
\frac{\partial^{2} E(T P U(S, Y))}{\partial S \partial Y} & \frac{\partial^{2} E(T P U(S, Y))}{\partial S^{2}}
\end{array}\right] .
$$

Buradan, sıfırdan farklı herhangi $Y$ ve $S$ değerleri için, eğer

$$
\begin{aligned}
& \frac{\partial^{2} E(T P U(S, Y))}{\partial Y^{2}}<0, \\
& \frac{\partial^{2} E(T P U(S, Y))}{\partial S^{2}}<0
\end{aligned}
$$

ve

$$
[Y S] \times[H E] \times\left[\begin{array}{l}
Y \\
S
\end{array}\right]<0
$$

Ya da

$$
\begin{aligned}
& {[Y S] \times[H E] \times\left[\begin{array}{l}
Y \\
S
\end{array}\right]} \\
& =\left[Y^{2} \frac{\partial^{2} E(T P U(S, Y))}{\partial Y^{2}}+2 Y S \frac{\partial^{2} E(T P U(S, Y))}{\partial Y \partial S}+\right. \\
& \left.S^{2} \frac{\partial^{2} E(T P U(S, Y))}{\partial S^{2}}\right]<0
\end{aligned}
$$

olduğu gösterilirse, birim zamandaki beklenen toplam kâr $(E(T P U(S, Y)))$ fonksiyonu kesinlikle konkav bir fonksiyondur denilir. 0 halde, hessian matrisi oluşturan elemanlar aşağıdaki gibi elde edilir:

$$
\begin{aligned}
& \frac{\partial^{2} E(T P U(S, Y))}{\partial Y^{2}}=-\frac{2 K(a-b S)}{Y^{3}}\left[\frac{1}{1-E(P)}\right]<0, \\
& \frac{\partial^{2} E(T P U(S, Y))}{\partial S^{2}}=-\frac{2 b^{2}\left(d_{1}-d_{2}\right)}{\alpha}\left[\frac{E\left(\frac{1}{1-P}\right)}{(1-E(P))}\right] \\
& -2 b\left[\frac{1-A E(P)}{1-E(P)}\right]+\frac{2 h b^{2} Y}{\alpha X}\left[\frac{E(P) E\left(\frac{1}{1-P}\right)}{(1-E(P))}\right]<0, \quad(32) \\
& \frac{\partial^{2} E(T P U(S, Y))}{\partial Y \partial S}=-\frac{h b}{2}\left[\frac{1}{\alpha}\left(\frac{1-2 E(P)}{1-E(P)}\right)-\frac{2}{X}\left(\frac{E(P)}{1-E(P)}\right)\right] \\
& -\frac{K b}{Y^{2}}\left[\frac{1}{1-E(P)}\right]-\frac{2 h b(a-b S)}{\alpha X}\left[\frac{E(P) E\left(\frac{1}{1-P}\right)}{1-E(P)}\right]
\end{aligned}
$$

ve

$$
\begin{aligned}
& \frac{\partial^{2} E(T P U(S, Y))}{\partial S \partial Y}=-\frac{h b}{2}\left[\frac{1}{\alpha}\left(\frac{1-2 E(P)}{1-E(P)}\right)-\frac{2}{X}\left(\frac{E(P)}{1-E(P)}\right)\right] \\
& -\frac{K b}{Y^{2}}\left[\frac{1}{1-E(P)}\right]-\frac{2 h b(a-b S)}{\alpha X}\left[\frac{E(P) E\left(\frac{1}{1-P}\right)}{1-E(P)}\right] .
\end{aligned}
$$

Literatür incelendiğinde, kusurlu ürün oranının beklenen değerinin $0 \leq E(P) \leq 1 / 3$ aralığında alındığı görülür (Chung, 2013). Dolayısıyla, diğer tüm ifadeler tanımı gereği pozitif olduklarından, (31) eşitliğindeki koşul sağlanmaktadır. Bununla birlikte, (32) eşitliğindeki koşulunda sağlanması gerekmektedir.

Yukarıda elde edilen eşitlikler (31)-(34), (30) eşitliğinde yerlerine yazılırsa aşağıdaki ifade elde edilir:

$$
\begin{aligned}
& -\frac{2 K a}{Y}\left[\frac{1}{1-E(P)}\right]-2 b^{2}\left[\frac{1-A E(P)}{1-E(P)}\right]- \\
& \frac{4 h b a S Y}{\alpha X}\left[\frac{E(P) E\left(\frac{1}{1-P}\right)}{1-E(P)}\right]+\frac{6 h b^{2} S^{2} Y}{\alpha X}\left[\frac{E(P) E\left(\frac{1}{1-P}\right)}{(1-E(P))}\right] \\
& -h b S Y\left[\frac{1}{\alpha}\left(\frac{1-2 E(P)}{1-E(P)}\right)-\frac{2}{X}\left(\frac{E(P)}{1-E(P)}\right)\right]<0 .
\end{aligned}
$$

Ayrıca, (35) eşitliğinde verilen koşulunda sağlanması gerekmektedir. Sonuç olarak, (32) ve (35) eşitliğinde verilen her iki koşulda 


\section{H. ÖZTÜRK}

sağlandığında, birim zamandaki beklenen toplam kâr $(E(T P U(S, Y)))$ konkav bir fonksiyon olmaktadır.

Birim zamandaki beklenen toplam kârı maksimum yapan satış fiyatı $(S)$ ve üretim miktarını $(Y)$ bulmak için, birim zamanda beklenen toplam kâr $(E(T P U(S, Y)))$ fonksiyonunun sırasiyla satış fiyatı $(S)$ ve üretim miktarına $(Y)$ göre birinci mertebeden kısmi türevleri sıfıra eșitlenir,

$$
\begin{aligned}
& \frac{\partial E(T P U(S, Y))}{\partial Y}=\frac{K(a-b S)}{Y^{2}}\left[\frac{1}{1-E(P)}\right]-\frac{h}{2}\left[\frac{1-2 E(P)}{1-E(P)}+\right. \\
& \left.\frac{E\left(P^{2}\right)}{1-E(P)}\right]+\frac{h(a-b S)}{2}\left[\frac{1}{\alpha}\left(\frac{1-2 E(P)}{1-E(P)}\right)-\frac{2}{X}\left(\frac{E(P)}{1-E(P)}\right)\right] \\
& +\frac{h b(a-b S)^{2}}{\alpha X}\left[\frac{E(P) E\left(\frac{1}{1-P}\right)}{1-E(P)}\right]=0
\end{aligned}
$$

ve

$$
\begin{aligned}
& \frac{\partial E(T P U(S, Y))}{\partial S}=(a-2 b S)\left[\frac{1-A E(P)}{1-E(P)}\right]+ \\
& \frac{K b}{Y}\left[\frac{1}{1-E(P)}\right]+C_{P} b\left[\frac{1}{1-E(P)}\right]+d_{2} b\left[\frac{1}{1-E(P)}\right] \\
& +\frac{2 b\left(d_{1}-d_{2}\right)(a-b S)}{\alpha}\left[\frac{E\left(\frac{1}{1-P}\right)}{(1-E(P))}\right]- \\
& \frac{h b Y}{2}\left[\frac{1}{\alpha}\left(\frac{1-2 E(P)}{1-E(P)}\right)-\frac{2}{X}\left(\frac{E(P)}{1-E(P)}\right)\right] \\
& -\frac{2 h b Y(a-b S)}{\alpha X}\left[\frac{E(P) E\left(\frac{1}{1-P}\right)}{1-E(P)}\right]=0 .
\end{aligned}
$$

Yukarıdaki eşitliklerden, üretim miktarı ve satış fiyatı için sırasıyla aşağıdaki ifadeler elde edilir

$$
Y=\sqrt{\frac{2 K\left[\frac{1}{1-E(P)}\right]}{X_{1}-X_{2}}}
$$

ve

$$
S_{Y}=\frac{a}{2 b}+\frac{X_{3}+X_{4}-X_{5}-X_{6}}{X_{7}} .
$$

Burada, $X_{i}$ 'ler aşağıdaki gibidir.

$$
X_{1}=\frac{h}{\left(a-b S^{*}\right)}\left[\frac{1-2 E(P)}{1-E(P)}+\frac{E\left(P^{2}\right)}{1-E(P)}\right] \text {, }
$$

$$
\begin{aligned}
& X_{2}=h\left[\frac{1}{\alpha}\left(\frac{1-2 E(P)}{1-E(P)}\right)-\frac{2}{X}\left(\frac{E(P)}{1-E(P)}\right)-\right. \\
& \left.\frac{2(a-b S)}{\alpha X}\left(\frac{E(P) E\left(\frac{1}{1-P}\right)}{1-E(P)}\right)\right], \\
& X_{3}=\left(\frac{K}{Y}+C_{P}+d_{2}\right)\left[\frac{1}{1-E(P)}\right], \\
& X_{4}=\frac{\left(d_{1}-d_{2}\right) a}{\alpha}\left[\frac{E\left(\frac{1}{1-P}\right)}{(1-E(P))}\right], \\
& X_{5}=\frac{h Y}{2}\left[\frac{1}{\alpha}\left(\frac{1-2 E(P)}{1-E(P)}\right)-\frac{2}{X}\left(\frac{E(P)}{1-E(P)}\right)\right], \\
& X_{6}=\frac{h a Y}{\alpha X}\left[\frac{E(P) E\left(\frac{1}{1-P}\right)}{1-E(P)}\right], \\
& X_{7}=2\left[\frac{1-A E(P)}{1-E(P)}+\frac{\left(d_{1}-d_{2}\right) b}{\alpha}\left[\frac{E\left(\frac{1}{1-P}\right)}{(1-E(P))}\right]-\right. \\
& \left.\frac{h b Y}{\alpha X}\left[\frac{E(P) E\left(\frac{1}{1-P}\right)}{1-E(P)}\right]\right] .
\end{aligned}
$$

(38) ve (39) eşitlikleri incelendiğinde, çalışmaya konu olan envanter probleminin karar değişkenleri olan satış fiyatı ve üretim miktarının birbiri ile bağlantılı olduğu görülmektedir. Yani, üretim miktarının satış fiyatının bir fonksiyonu olduğu ve benzer olarak satış fiyatının üretim miktarının bir fonksiyonu olduğu açıktır. Dolayısıyla, ilgili eşitliklerden direkt olarak her iki karar değişkenin çözüm değerlerine ulaşılamadığından, üretim miktarı ve satış fiyatının çözüm değerleri önerilen bir algoritma yardımıyla elde edilecektir. Üretim miktarı $(Y)$ ve sipariş fiyatının $(S)$ optimal çözümlerini $\left(S^{*}, Y^{*}\right)$ elde etmek için aşağıdaki algoritma önerilmiştir. $\mathrm{Bu}$ algoritmanın bir kısmı Taleizadeh vd. (2016)'nin çalışmasından uyarlanmıştır.

Algoritma:

\section{Adım Başla.}

2. Adım Eğer, $E(P) \leq 1-\beta / \alpha \quad$ ve $\beta(1-\beta / \alpha E(1 /(1-P))) /(1-$ $E(P)-\beta / \alpha)<X$ ise 3. Adım'a 
git. Değilse, problem olursuz hale gelir, 8. Adım'a git.

3. Adım $\quad Y=1$ için, (39) eşitliğinden satış fiyatını $\left(S_{Y}\right)$ hesapla.

4. Adım (32) ve (35) eşitliklerini kullanarak birim zamandaki beklenen toplam kâr $E\left(T P U\left(S_{Y}, Y\right)\right)$ fonksiyonunun konkavlığını kontrol et. Eğer $E\left(T P U\left(S_{Y}, Y\right)\right)$ konkav ise 5 . Adım'a git. Değilse, NewtonRaphson yöntemini kullanarak lokal maksimum noktayı belirle.
5. Adım $E\left(T P U\left(S_{Y}, Y\right)\right)$ hesapla.

6. Adım

$Y=Y+1 \quad$ için, birim zamandaki beklenen toplam kâr $\quad E\left(T P U\left(S_{Y}, Y\right)\right)$ fonksiyonun değerini elde etmek için 3-5. adımı tekrar et.

7. Adım

$\begin{array}{ll}\text { Eğer } & E\left(T P U\left(S_{Y}, Y\right)\right) \geq \\ E\left(T P U\left(S_{Y-1}, Y-1\right)\right) \text { ise } 6 .\end{array}$

Adım'a git, değilse, birim zamandaki beklenen toplam kârın maksimum değeri olarak $E\left(T P U\left(S^{*}, Y^{*}\right)\right)=$ $E\left(T P U\left(S_{Y-1}, Y-1\right)\right)$ belirle. 0 halde, $\left(S^{*}, Y^{*}\right)$ ikilisi optimal çözümdür.

\section{Adım Bitir.}

\section{2. Özel durum}

Çalıșmada ele alınan problem de üretilen tüm ürünlerin sadece kusursuz ürünlerden oluştuğunu yani hiçbir kusurlu ürün üretilmediğini düşünelim. $\mathrm{Bu}$ durumda, kusurlu ürün oranı sıfirdır $(P=0)$. 0 halde, (23), (38) ve (39) eşitlikleri sırasıyla aşağıdaki eșitliklere indirgenir.

$$
E(T P U(S, Y))=(a-b S) S-\frac{K(a-b S)}{Y}
$$

$$
\begin{aligned}
& -C_{P}(a-b S)-d_{2}(a-b S) \\
& -\frac{\left(d_{1}-d_{2}\right)(a-b S)^{2}}{\alpha}-\frac{h Y}{2}+\frac{h Y(a-b S)}{2 \alpha}, \\
& Y=\sqrt{\frac{2 K}{h\left(\frac{1}{(a-b S)}-\frac{1}{\alpha}\right)}} \\
& \text { ve } \\
& S_{Y}=\frac{a}{2 b}+\frac{\left(d_{1}-d_{2}\right) a+\alpha\left(\frac{K}{Y}+C_{P}+d_{2}\right)-\frac{h Y}{2}}{2\left(\alpha+\left(d_{1}-d_{2}\right) b\right)} .
\end{aligned}
$$

\section{SAYISAL ÖRNEK VE DUYARLILIK ANALİZí}

Bu bölümde, geliștirilen stok kontrol modelinin hem uygulanabilirliğini ve geçerliliğini göstermek hem de önerilen algoritma ile optimal çözümü elde etmek için sayısal bir örnek verilmektedir. Tek kalem ürünün tek bir makinede yıllık $\alpha=1600$ birim üretim hızıyla partiler halinde üretildiğini ve bu ürüne karşı olan talebin satış fiyatına karşı duyarlı olduğunu ve satış fiyatının doğrusal bir fonksiyonu olduğunu varsayalım. Bu durumda, satış fiyatının doğrusal bir fonksiyonu olarak talep $\beta(S)=1000-2 S>0$ biçiminde verilsin. Ayrıca, üretilen herbir partide $P$ oranında kusurlu ürün bulunmaktadır ve kusurlu ürün oranı $(P),[0, r]$ aralığında sürekli tekdüze dağılıma uyan rassal bir değişkendir. $\mathrm{Bu}$ durumda, olasılık yoğunluk fonksiyonu aşağıdaki gibidir. Burada $r$ ile kusurlu ürün oranının $(P)$ tanımlı olduğu aralığın üst limit değeri ifade edilmektedir.

$$
f(P)=\left\{\begin{array}{c}
10,0 \leq P \leq r=0.1 \\
0, \text { diğer durumlarda } .
\end{array}\right.
$$

Probleme ilișkin parametre değerleri Tablo 1'de özetlenmiștir. İlgili parametrelere ilișkin değerlerin büyük bir kısmı Moussawi-Haidar vd. (2016)'nın çalışmasından alınmıştır, bu çalıșmada ele alınan problemde kullanılan diğer parametre değerleri uygun olarak seçilmiştir.

Ayrıca, tekdüze dağılımdan aşağıdaki beklenen değerler elde edilebilir: 


\section{H. ÖZTÜRK}

$$
\begin{array}{ll}
E(P)=\int_{0}^{0.1} P f(P) d P=10 \int_{0}^{0.1} P d P=0,05, & E\left(\frac{1}{1-P}\right)=\int_{0}^{0.1}\left(\frac{1}{1-P}\right) 10 d P= \\
E\left(P^{2}\right)=\int_{0}^{0.1} P^{2} 10 d P=10 \int_{0}^{0.1} P^{2} d P= & 10 \int_{0}^{0.1}\left(\frac{1}{1-P}\right) d P=1,053605 .
\end{array}
$$

0,003333 ,

Tablo 1: Problem için gerekli parametre değerleri

\begin{tabular}{lcl}
\hline Parametre & Notasyon & Değer \\
\hline Üretim hızı & $\alpha$ & 1600 birim/yl \\
Tarama hızı & $X$ & 175200 birim/yl \\
Üretim hazırlık maliyeti & $K$ & $\$ 1500 /$ çevrim \\
Birim tarama maliyeti (Üretim sırasında) & $d_{1}$ & $\$ 0,6 / \mathrm{birim}$ \\
Birim tarama maliyeti (Üretimden sonra) & $d_{2}$ & $\$ 0,5 / \mathrm{birim}$ \\
Stokta tutma maliyeti & $h$ & $\$ 20 / \mathrm{birim} / \mathrm{yl}$ \\
Birim üretim maliyeti & $C_{P}$ & $\$ 104 / \mathrm{birim} / \mathrm{yll}$ \\
İndirim oranı & $A$ & 0,60 \\
\hline
\end{tabular}

Tablo 2: Üretim miktarı $(Y)$ ve satış fiyatının $(S)$ optimal çözümünü elde etmek için algoritmadaki

\begin{tabular}{|c|c|c|c|c|c|c|}
\hline$Y$ & $S_{Y}$ & $E\left(T P U\left(S_{Y}, Y\right)\right)$ & $1-\frac{\beta}{\alpha}$ & $\frac{\beta\left(1-\frac{\beta}{\alpha} E\left(\frac{1}{1-P}\right)\right)}{1-E(P)-\frac{\beta}{\alpha}}$ & $\begin{array}{l}\text { Eşitlik (32) deki } \\
\text { koşul }\end{array}$ & $\begin{array}{r}\text { Eşitlik } \\
\text { (35) teki } \\
\text { koşul }\end{array}$ \\
\hline 286 & 305,77 & 74332,19 & 0,75721 & 408,78 & $-4,084756003$ & $-13119,06$ \\
\hline 287 & 305,75 & 74332,45 & 0,75719 & 408,81 & $-4,084755971$ & $-13087,73$ \\
\hline 288 & 305,74 & 74332,66 & 0,75718 & 408,83 & $-4,084755940$ & $-13056,68$ \\
\hline 289 & 305,73 & 74332,82 & 0,75716 & 408,86 & $-4,084755908$ & $-13025,89$ \\
\hline 290 & 305,72 & 74332,93 & 0,75715 & 408,88 & $-4,084755876$ & $-12995,36$ \\
\hline 291 & 305,71 & 74332,99 & 0,75713 & 408,91 & $-4,084755845$ & $-12965,09$ \\
\hline $292^{*}$ & $305,69 *$ & $74333,00 *$ & 0,75712 & 408,94 & $-4,084755813$ & $-12935,08$ \\
\hline 293 & 305,68 & 74332,97 & 0,75710 & 408,96 & $-4,084755782$ & $-12905,32$ \\
\hline 294 & 305,67 & 74332,88 & 0,75708 & 408,99 & $-4,084755750$ & $-12875,81$ \\
\hline 295 & 305,66 & 74332,75 & 0,75707 & 409,01 & $-4,084755718$ & $-12846,55$ \\
\hline 296 & 305,65 & 74332,57 & 0,75706 & 409,03 & $-4,084755687$ & $-12817,54$ \\
\hline 297 & 305,64 & 74332,34 & 0,75704 & 409,06 & $-4,084755655$ & $-12788,77$ \\
\hline 298 & 305,62 & 74332,07 & 0,75703 & 409,08 & $-4,084755623$ & $-12760,24$ \\
\hline 299 & 305,61 & 74331,75 & 0,75701 & 409,11 & $-4,084755592$ & $-12731,95$ \\
\hline 300 & 305,60 & 74331,38 & 0,75700 & 409,13 & $-4,084755560$ & $-12703,89$ \\
\hline
\end{tabular}
adımlar

*0ptimal çözüm 


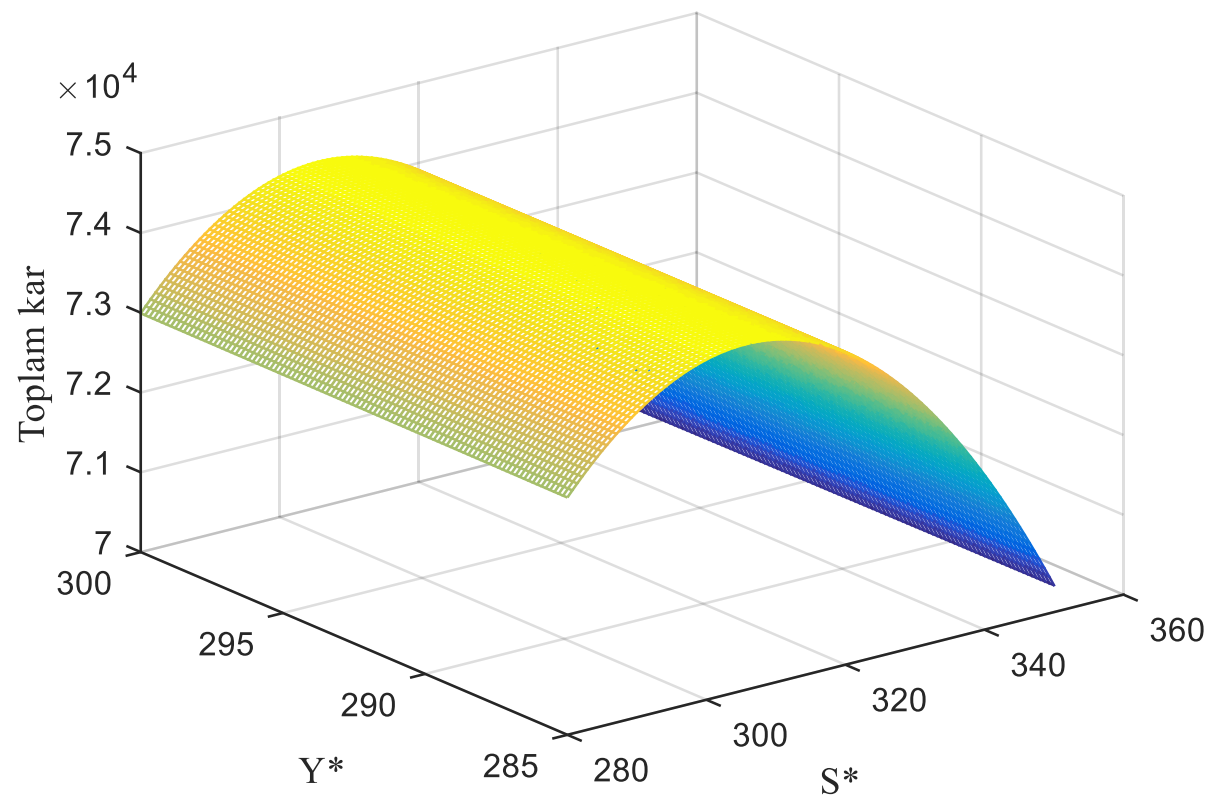

Şekil 2: Toplam kâr fonksiyonunun üretim miktarı $(Y)$ ve satış fiyatına $(S)$ göre değişimi.

\subsection{Duyarlılık analizi}

Geliștirilen model parametrelerinden, üretim hızı $(\alpha)$, üretim hazırlık maliyeti $(K)$, üretim sirasinda birim tarama maliyeti $\left(d_{1}\right)$, üretimden sonra birim tarama maliyeti $\left(d_{2}\right)$, üretimden sonra tarama hızı $(X)$, birim üretim maliyeti $\left(C_{p}\right)$, stokta tutma maliyeti $(h)$ ve olasılık yoğunluk fonksiyonunun $(f(P))$ tanıml olduğu aralığın üst limit değerinin $(r)$ optimal çözüm sonuçları üzerindeki etkisi duyarlılık analizi yardımıyla yapılacaktır. İlgili parametre değerlerinin önce $-\% 50$ ve $-\% 25$ oranlarında azaldığ oranlarında arttığı varsayılmış ve elde edilen sonuçlar Tablo 3'te verilmiştir. Ayrıca, ilgili parametrelerdeki değişimlerin toplam kâr, birim satış fiyatı ve üretim miktarı üzerindeki etkileri Şekil 3-5'te gösterilmiştir.

Tablo 3 'ten aşağıdaki sonuçlar çıkarılabilir:

Üretim hızı $(\alpha)$ arttığında, optimal üretim miktarı $\left(Y^{*}\right)$ ve yıllık beklenen toplam kâr $(E(T P U(S, Y)))$ azalmaktadır, birim satış fiyatı $\left(S^{*}\right)$ artmaktadır. $\alpha, \% 50$ arttığında, üretim miktarı ve yıllık beklenen toplam kar sırasıyla $\% 5.13699$ ve \%0.28825 azalmaktadır, birim satış fiyatı \%0.14586 artmaktadır. Bu durumda, üretim miktarının üretim hızındaki değișimlerden zit yönde ve daha fazla etkilendiği söylenebilir.

Üretim hazırlık maliyeti $(K)$ arttığında, optimal üretim miktarı $\left(Y^{*}\right)$ ve birim satış fiyatı $\left(S^{*}\right)$ artmaktadır, yıllık beklenen toplam kâr $(E(T P U(S, Y))) \quad$ azalmaktadır. $K, \quad \% 50$ arttığında, üretim miktarı ve birim satış fiyatı sirasiyla $\% 22.26027$ ve \%0.13489 artmaktadır, yıllık beklenen toplam kâr \%1.27137 azalmaktadır.

Optimal üretim miktarı $\left(Y^{*}\right)$, üretim sırasında tarama maliyeti $\left(d_{1}\right)$ ve üretimden sonra tarama maliyetindeki $\left(d_{2}\right)$ değişimlerden etkilenmezken, birim satış fiyatı aynı yönde, yılllık beklenen toplam kâr ise zıt yönde etkilenmektedir. $\quad d_{1}>d_{2}$ koşulu dikkate alınmadığında, tarama işleminin üretim sırasında yapılmasının yıllık beklenen toplam kârda bir azalmaya sebep olduğu görülebilir. Diğer taraftan, üretimden sonraki tarama hızı $(X)$ arttığında, birim satış fiyatı azalmaktadır, ancak ylllık beklenen toplam kâr $\operatorname{E(TPU}(S, Y))$ artmaktadır. $\mathrm{Bu}$ durum, tarama işleminin ne zaman yapılması gerektiği (üretim sırasında, üretimden sonra, hem üretim sırasında hem üretim sonrasında) konusunda işletmelere bir alternatif sunmaktadır. 


\section{H. ÖZTÜRK}

Tablo 3: Duyarlılık analizi sonucunda parametrelerdeki ve optimal çözümdeki (\%) değişimler

\begin{tabular}{|c|c|c|c|c|}
\hline \multirow{2}{*}{ Parametre } & \multirow{2}{*}{ Değişim (\%) } & \multicolumn{3}{|c|}{ Değişimler (\%) } \\
\hline & & $Y$ & $S$ & $E(T P U(S, Y))$ \\
\hline \multirow[t]{4}{*}{$\alpha$} & -50 & +22.26027 & -0.54934 & +0.98333 \\
\hline & -25 & +5.82192 & -0.15861 & +0.30552 \\
\hline & +25 & -3.08219 & +0.08806 & -0.17485 \\
\hline & +50 & -5.13699 & +0.14586 & -0.28825 \\
\hline \multirow[t]{4}{*}{$K$} & -50 & -29.10959 & -0.17465 & +1.65826 \\
\hline & -25 & -13.35616 & -0.07942 & +0.75833 \\
\hline & +25 & +11.64384 & +0.07138 & -0.66783 \\
\hline & +50 & +22.26027 & +0.13489 & -1.27137 \\
\hline \multirow{4}{*}{$d_{1}$} & -50 & 0 & $-0,02591$ & 0,04227 \\
\hline & -25 & 0 & $-0,01296$ & 0,02113 \\
\hline & +25 & 0 & 0,01293 & $-0,02112$ \\
\hline & +50 & 0 & 0,02586 & $-0,04223$ \\
\hline \multirow[t]{4}{*}{$d_{2}$} & -50 & 0 & $-0,02058$ & 0,10238 \\
\hline & -25 & 0 & $-0,01030$ & 0,05119 \\
\hline & +25 & 0 & 0,02057 & $-0,10236$ \\
\hline & +50 & 0 & 0,01028 & $-0,05118$ \\
\hline \multirow[t]{4}{*}{$X$} & -50 & 0 & 0,00013 & $-0,00068$ \\
\hline & -25 & 0 & 0,00003 & $-0,00023$ \\
\hline & +25 & 0 & $-0,00004$ & 0,00014 \\
\hline & +50 & 0 & $-0,00006$ & 0,00023 \\
\hline \multirow[t]{4}{*}{$C_{P}$} & -50 & +9.24658 & -8.86601 & +30.61204 \\
\hline & -25 & +4.45205 & -4.43280 & +14.80710 \\
\hline & +25 & -4.79452 & +4.44044 & -13.80848 \\
\hline & +50 & -9.24658 & +8.88095 & -26.61740 \\
\hline \multirow[t]{4}{*}{$h$} & -50 & +41.43836 & -0.17270 & +1.65826 \\
\hline & -25 & +15.41096 & -0.07844 & +0.75833 \\
\hline & +25 & -10.61644 & +0.07040 & -0.66783 \\
\hline & +50 & -18.49315 & +0.13489 & -1.27137 \\
\hline \multirow[t]{4}{*}{$r$} & -50 & -2.39726 & -0.26500 & -0.24346 \\
\hline & -25 & -1.36986 & -0.13174 & -0.12337 \\
\hline & +25 & +1.02740 & +0.13819 & +0.12676 \\
\hline & +50 & +2.05479 & +0.27889 & +0.25705 \\
\hline
\end{tabular}

Birim üretim maliyetinin $\left(C_{p}\right)$, optimal üretim miktarı $\left(Y^{*}\right)$ ve ylllık beklenen toplam kâr $E(T P U(S, Y))$ üzerinde zit yönde etkisi bulunurken, birim satış fiyatı $\left(S^{*}\right)$ üzerinde aynı yönde etkisi bulunmaktadır. $C_{p}$ arttığında, üretim miktarı ve yıllık beklenen toplam kar azalmaktadır, ancak birim satıș fiyatı artmaktadır. Yıllık beklenen toplam kârın birim üretim miktarındaki değişimlerden daha fazla etkilendiği söylenebilir.
Stokta tutma maliyetinin $(h)$, yıllık beklenen toplam kâr ve üretim miktarı $\left(Y^{*}\right)$ üzerinde aynı yönde etkisi bulunurken, birim satış fiyatı $\left(S^{*}\right)$ üzerinde zıt yönde etkisi bulunmaktadır. $h$ arttığında, üretim miktarı ve yıllık beklenen toplam kâr azalmaktadır, birim satış fiyatı artmaktadır.

Son olarak, olasılık yoğunluk fonksiyonunun parametresindeki $(r) \quad$ değișimler incelendiğinde, optimal çözümlerinde aynı 
İzmir İktisat Dergisi (İzmir Journal of Economics) , Yıl:2019, Cilt:34, Sayı:3, ss. 413-430

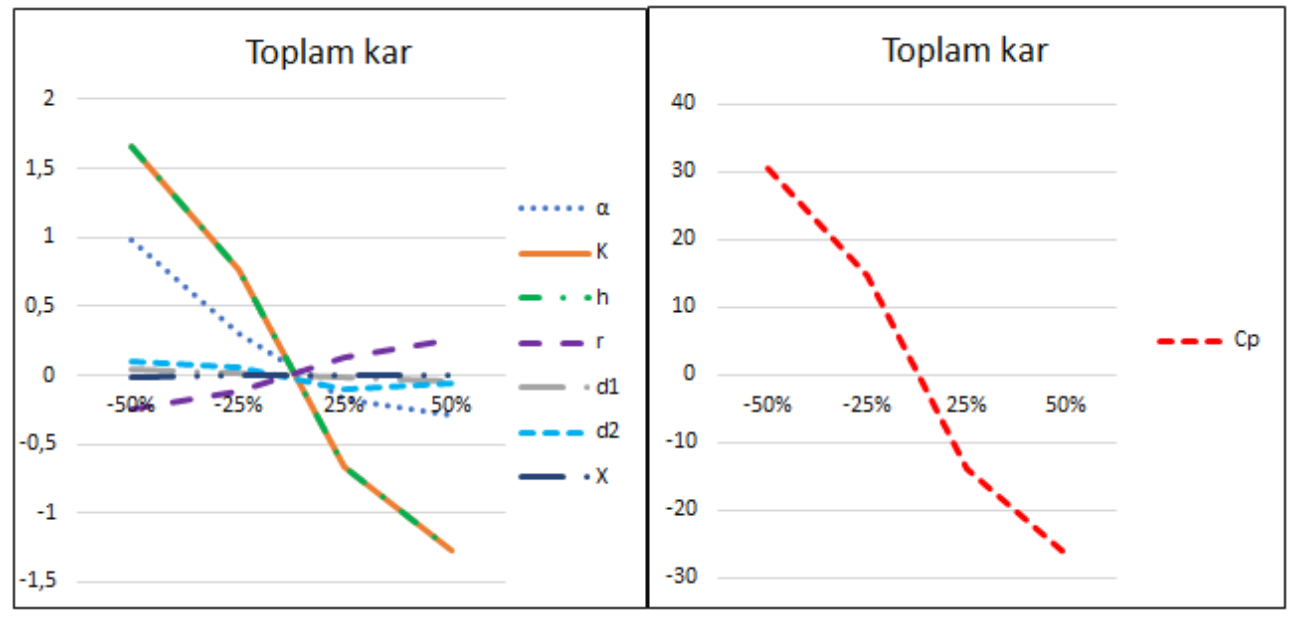

Şekil 3: Parametrelerdeki yüzdesel değişimlerin toplam kâr üzerindeki yüzdesel etkileri

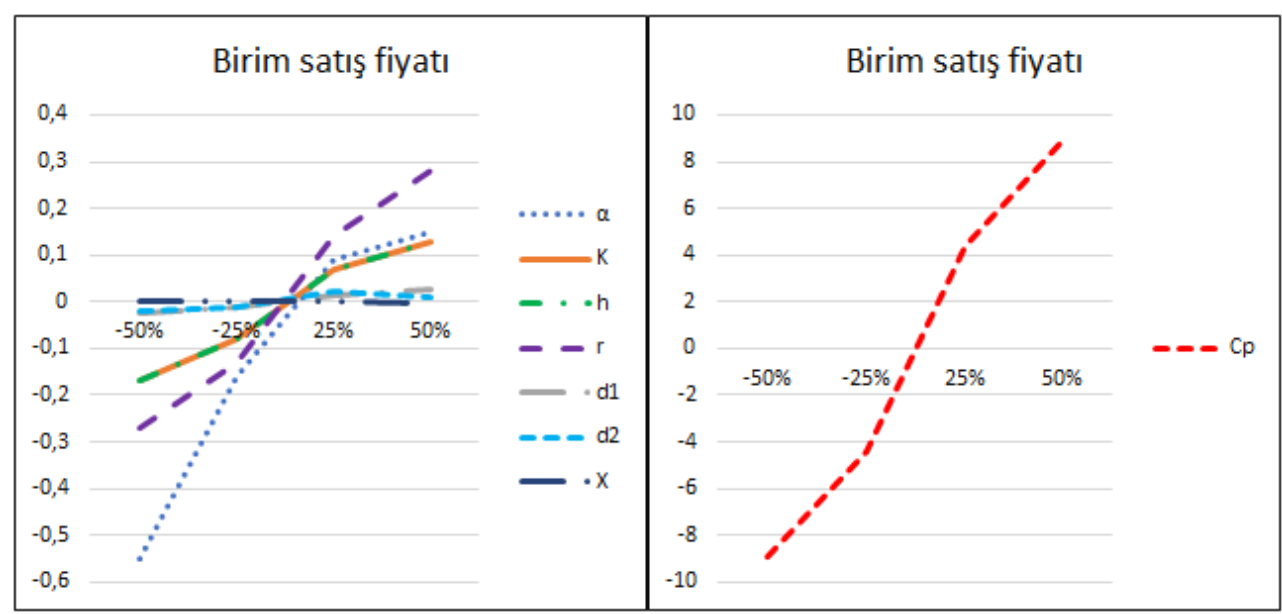

Şekil 4: Parameterlerdeki yüzdesel eğişimlerin birim satış fiyatı üzerindeki yüzdesel etkileri

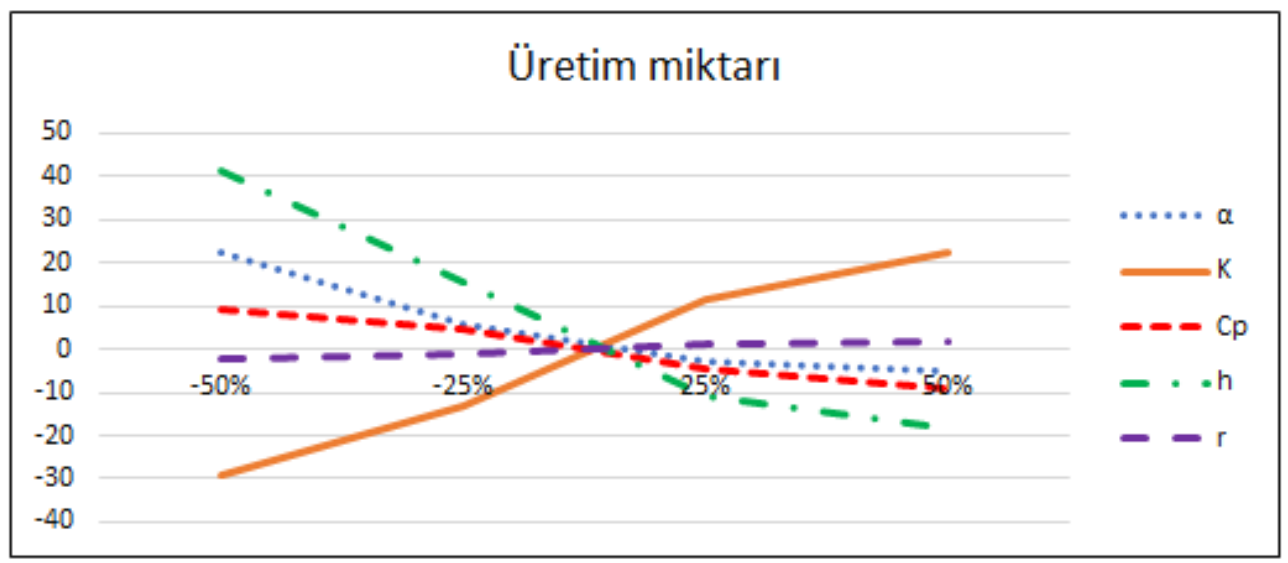

Şekil 5: Parametrelerki yüzdesel değişimlerin üretim miktarı üzerindeki yüzdesel etkileri

yönde etkilendiği görülmektedir. $r$ arttığında, bir bașka ifade ile kusurlu ürün oranının beklenen değeri $(E(P))$ arttığında, talep miktarının birim satış fiyatının bir fonksiyonu 


\section{H. ÖZTÜRK}

olması varsayımı altında optimal üretim miktarı $\left(Y^{*}\right)$, birim satış fiyatı $\left(S^{*}\right)$ ve yıllık beklenen toplam kâr artmaktadır.

Son olarak, olasılık yoğunluk fonksiyonunun parametresindeki $(r) \quad$ değişimler incelendiğinde, optimal çözümlerinde aynı yönde etkilendiği görülmektedir. $r$ arttığında, bir başka ifade ile kusurlu ürün oranının beklenen değeri $(E(P))$ arttığında, talep miktarının birim satış fiyatının bir fonksiyonu olması varsayımı altında optimal üretim miktarı $\left(Y^{*}\right)$, birim satış fiyatı $\left(S^{*}\right)$ ve yıllık beklenen toplam kâr artmaktadır. Bu çalışmada, üretim sırasında üretilen kusurlu ürünlerin tarama süresi sonunda stoktan çıkarıldığı ve indirimli fiyattan satıldığı varsayılmaktadır. Bununla birlikte, ilgili ürüne olan talep sadece kusursuz ürünlerden karşılanacağından, üretilen kusurlu ürün miktarının artması üretim miktarının artmasına yol açmaktadır.

\section{SONUÇ}

$\mathrm{Bu}$ çalıșmada, kusurlu üretim sistemi çerçevesinde tek kalem ürünün tek bir makinede partiler halinde üretildiği bir stok kontrol problemi için matematiksel bir model geliştirilmiştir. Üretim sisteminde üretilen herbir parti, kusursuz ürünler ile birlikte indirimli fiyattan satılabilir kusurlu ürünler içermektedir. Stoksuz kalma durumuna izin verilmemiştir. Kusurlu ürünleri belirlemek için üretimin başladığı andan itibaren bir tarama işlemi yapılmaktadır. Üretim sırasında müşteriye teslim edilen herbir partinin sadece kusursuz ürünlerden oluşması amacıyla tarama işlemi manuel (el ile) olarak yapılmaktadır. Üretim tamamlandıktan sonra ise talep hızından daha büyük bir tarama hızı ile otomasyona dayalı bir tarama yapılmaktadır. Tüm kusurlu ürünler tarama ișlemi tamamlanıncaya kadar stokta bekletilmektedir ve tarama tamamlandığında tek parti halinde indirimli fiyattan satılmaktadır.

Fiyatlandırma, endüstride ve herhangi bir iş kolunda faaliyet gösteren her işletme için kârını maksimuma çıkarmada en önemli faktörlerden biri olduğundan, bu çalışmada, talep miktarının satıș fiyatının doğrusal bir fonksiyonu olduğu varsayılmıştır. Dolayısıyla bu çalışmada önerilen stok kontrol modeli, üretim miktarını ve satış fiyatını birlikte optimum yapmayı sağlamaktadır. Optimal çözümler geliștirilen bir algoritma yardımıyla elde edilmiştir. Ayrıca, üretilen tüm ürünlerin sadece kusursuz ürünlerden olușması durumu, önerilen modelin özel bir hali olarak ele alınmıștır. Son olarak, önerilen modelin uygulanabilirliğini ve geçerliliğini göstermek amacıyla duyarlılık analizine imkan veren sayısal bir örnek verilmiştir. Duyarlılık analizleri sonucunda, üretim miktarınının stokta tutma maliyetindeki değişimlerden önemli ölçüde etkilendiği elde edilirken, satıș fiyatının birim üretim maliyetindeki değişimlerden oldukça fazla etkilendiği görülmektedir. Toplam kâr, birim üretim maliyetindeki değişimlerden önemli ölçüde etkilenirken, üretime hazırlık maliyeti ve stokta tutma maliyetindeki değişimlerden daha az ve aynı düzeyde etkilenmektedir. Yine duyarlılık analizi sonuçlarından, üretimden sonraki tarama hızının artmasıyla kusurlu ürünlerin daha kısa sürede elden çıkarılması sağlandığından yıllık beklenen toplam karda artış olduğu görülmektedir.

Talep miktarının satış fiyatına bağlı olması ve tarama işleminin hem üretim sırasında hem de üretimden sonra gerçekleşmesi varsayımlarının optimal üretim miktarı, birim satış fiyatı ve toplam kâr üzerindeki ortak etkisi, bu çalışmada elde edilen sonuçlar yardımıyla daha da anlaşılır hale gelmiştir. Ancak yine de, bu çalıșma bazı kısıtlamalar içermektedir. Örneğin, üretim sırasında üretilen kusurlu ürünlerin belirlenmesi için gerçekleştirilen tarama işlemi (otomasyon/mekanik ya da el ile), tam olarak güvenilir olmamaktadır. Bununla birlikte, kusurlu ürünlerin tam olarak belirlenmemesi eldeki kusursuz ürün miktarını etkileyeceğinden stoksuz kalma durumunun ortaya çıkmasına yol açacaktır. Tarama hatalarının (Tip 1 ve Tip 2) ve stoksuzluk durumunun birlikte modele dahil edilerek optimal çözüm üzerindeki etkisinin araştırılması oldukça ilginç ve gerçekçi olacaktır. Tedarikçiden temin edilen 
hammaddelerden kaynaklanan ödemenin siparişin teslim alınması anında yapıldı̆̆ varsayılmaktadır. Uygulamada tedarikçi, üreticiye ödemede belirli bir süre gecikmeye izin vermektedir ve bu gecikmeden dolayı fazladan bir ödeme talep etmemektedir. Ödemede belirli bir süre gecikmeye izin verilmesinin optimal politikada nasıl bir farklılık olușturacağının incelenmesi iki taraf içinde fayda sağlayabilmektedir. Ayrıca, bu çalışmada geliştirilen model, kısmi stoksuzluk, çok ürün, tedarikçinin üreticiye üreticininde müşterilerine ödemede belirli bir süre gecikmeye izin vermesi, çevresel duyarlılık ve makine arızalanması varsayımlarının dikkate alınmasıyla genişletilebilecektir.

\section{REFERANSLAR}

Abad, P. L. (2003). Optimal Pricing and Lotsizing under Conditions of Perishability, Finite Production and Partial Backordering and Lost Sale. European Journal of Operational Research, 144(3), 677-685.

Cárdenas-Barrón, L. E. (2009). Economic Production Quantity with Rework Process at A Single-Stage Manufacturing System with Planned Backorders. Computers and Industrial Engineering, 57, 1105-1113.

Chan, W. M., Ibrahim, R. N., ve Lochert, P. B. (2003). A New EPQ Model: Integrating Lower Pricing, Rework and Reject Situations", Production Planning \& Control, 14(7), 588-595.

Chen, J., ve Bell, P. C. (2009). The Impact of Customer Returns on Pricing and Order Decisions. European Journal of Operational Research, 195, 280-295.

Chiu, Y.-S. P. (2003). Determining The Optimal Lot Size for The Finite Production Model with Random Defective Rate, The Rework Process and Backlogging. Engineering Optimization, 35(4), 427-437.

Cunha, L. R. A., Delfino, A. P. S., Dos reis, K. A., ve Leiras, A. (2018). Economic Production Quantity (EPQ) Model with Partial Backordering and A Discount for Imperfect Quality Batches. International Journal of Production Research, 56(18), 6279-6293.

Dye, C.-Y. (2007). Joint Pricing and Ordering Policy for a Deteriorating Inventory with Partial Backlogging. Omega, 35(2), pp. 184189.
Emir, H., ve Gümüșoğlu, Ș. (1998). Üretim Yönetimi (İşlemler Yönetimi). Beta Yayıncılık, İstanbul.

Flapper, S. D. P., ve Teunter, R. H. (2004). Logistic Planning of Rework with Deteriorating Work-In-Process. International Journal of Production Economics, 88, 51-59.

Goyal, S. K. (1987). Note - Comment on: A Generalized Quantity Discount Pricing Model to Increase Supplier's Profits. Management Science, 33, 1635-1636.

Gürkan, M. E., Kaya, G. C., ve Kaya, M. F. (2017). Fiyata Bağımlı Deterministik Talep Varsayımı Altında Envanter Modellerini İnceleyen Bir Literatür Araştırmasi ve Sinıflandırması. Karabük Üniversitesi Sosyal Bilimler Enstitüsü Dergisi, 7(1), 162-188.

Harris, F. W. (1913). How Many Parts to Make at Once", Factory, The Magazine of Management 10(2), 135-136,152, reprinted (1990), Operations Research, 38, 947-950.

Hayek, P. A., ve Salameh, M. K. (2001). Production Lot Sizing with The Reworking of Imperfect Quality Items Produced. Production Planning \& Control, 12(6), 584-590.

Hsu, L.- F., ve Hsu, J.-T. (2014). Economic Production Quantity (EPQ) Models under An Imperfect Production Process with Shortages Backordered. International Journal of System Science, 47(4), 852-867.

Huang, Y., Huang, G. Q., ve Newman, S. T. (2011). Coordinating Pricing and Inventory Decisions in A Multi-Level Supply Chain: A Game-Theoretic Approach. Transportation 


\section{H. ÖZTÜRK}

Research Part E: Logistics and Transportation Review, 47(2), 115-129.

Jain, S., Tiwari, S., Cárdenas-Barrón, L. E., SHAIKH, A. A., ve SINGH, S. R. (2018). A Fuzzy Imperfect Production and Repair Inventory Model with Time Dependent Demand, Production and Repair Rates under Inflationary Conditions. RAIRO-Operations Research, 52(1), 217-239.

Jamal, A. M. M., Sarker, B. R., ve Mondal, S. (2004). Optimal Manufacturing Batch Size with Rework Process at A Single-Stage Production System. Computers and Industrial Engineering, 47(1), 77-89.

Koçer, U. U., ve Yalçin, B. (2013). Bir Stokastik Model Olarak Bozulabilir Envanter Problemi: Literatür Araştırması. Dokuz Eylül Üniversitesi İktisadi ve İdari Bilimler Fakültesi Dergisi, 28(1), 119-144.

Lau, H.-S., Lau, A. H.-L., ve Kottas, J. F. (2001). Pricing/inventory Decisions and Profit Shares in A Non-Integrated Marketing Channel for A Single-Period Product. Journal of the Operational Research Society, 52(6), 682-690.

Moussawi-Haidar, L., Salameh, M., ve Nasr, W. (2016). Production Lot Sizing with Quality Screening and Rework. Applied Mathematical Modelling, 40, 3242-3256.

Öztürk, H. (2017). A Note on "Production Lot Sizing with Quality Screening and Rework". Applied Mathematical Modelling, 43, 659-669.

Parlar, M., ve Weng, Z. K. (2006). Coordinating Pricing and Production Decisions in The Presence of Price Competition. European Journal of Operational Research, 170, 211-227.

Porteus, E. L. (1986). Optimal Lot Sizing, Process Quality Improvement and Setup Cost Reduction. Operations Research, 34, 137-144.

Rosenblatt, M. J., Lee, ve H. L. (1986). Economic Production Cycles with Imperfect Production Processes. IIE Transactions, 18(1), 48-55.

Ross, S. M. (1996). Stochastic Processes. Wiley, New York.
Sajadieh, M. S., ve Jokar, M. R. A. (2009). Optimizing Shipment, Ordering and Pricing Policies in A Two-Stage Supply Chain with Price-Sensitive Demand. Transportation Research Part E: Logistics and Transportation Review, 45(4), 564-571.

San-josé, L. A., Sicilia, J., ve Alcaide-López-dePablo, D. (2018). An Inventory System with Demand Dependent on Both Time and Price Assuming Backlogged Shortages. European Journal of Operational Research, 270(3), 889897.

Sarkar, B., Cárdenas-Barrón, L. E., Sarkar, M., ve Singgih, M. K. (2014). An Economic Production Quantity Model with Random Defective Rate, Rework Process and Backorders for A Single Stage Production System. Journal of Manufacturing Systems, 33, 423-435.

Shah, N. H., Patel, D. G., ve Shah, D. B. (2018). EPQ Model for Returned/Reworked Inventories During Imperfect Production Process under Price-Sensitive StockDependent Demand. Operational Research: An International Journal, 18(2), 343-359.

Shi, J., Zhang, G., ve Lai, K. K. (2012). Optimal Ordering and Pricing Policy with Supplier Quantity Discounts and Price-Dependent Stochastic Demand. Optimization, 61(2), 151162.

Taft, E. W. (1918). The Most Economical Production Lot. Iron Age, 101, 1410-1412.

Taleizadeh, A. A., Kalantari, S. S., ve CárdenasBarrón, L. E. (2016). Pricing and Lot Sizing for An EPQ Inventory Model with Rework and Multiple Shipments. TOP, 24, 143-155.

Taleizadeh, A. A., Yadegari, M., ve Sana, S. (2019). Production Models of Multiple Products Using Single Machine under Quality Screening and Reworking Policies. Journal of Modelling in Management, 14(1), 232-259.

Ulucan, A. (2004). Yöneylem Araştırması (İşletmecilik Uygulamalı ve Bilgisayar Destekli Modelleme). Siyasal Kitabevi, Ankara. 